\title{
Malignant pleural mesothelioma from nonoccupational asbestos exposure in Metsovo (north-west Greece): slow end of an epidemic?
}

\author{
K. Sakellariou*, V. Malamou-Mitsi**, A. Haritou*, C. Koumpaniou*, C. Stachouli*, I.D. \\ Dimoliatis\#, S.H. Constantopoulos*
}

\begin{abstract}
Malignant pleural mesothelioma from nonoccupational asbestos exposure in Metsovo (north-west Greece): slow end of an epidemic?. K. Sakellariou, V. Malamou-Mitsi, A. Haritou, C. Koumpaniou, C. Stachouli, I.D. Dimoliatis, S.H. Constantopoulos. C ERS Journals Ltd 1996.

ABSTRACT: Inhabitants of the Metsovo area, north-west Greece have been exposed since childhood to inhalation of asbestos, from a material containing tremolite, used for whitewashing ("luto soil"). This has resulted in endemic pleural calcifications (47\% of adult population) and increased incidence of malignant pleural mesothelioma (MPM). In 1987, we reported that the incidence of MPM between 1981-1985 was around 300 times higher than expected in a nonasbestos exposed population (seven cases in 5 yrs in a population of 4,000-5,000).

The present study is an updated report regarding this "mesothelioma epidemic", in conjunction with the diminished use and final abandonment of "luto soil" in the early 1980s.

It appears that the incidence of MPM in Metsovo has dropped considerably since our first report. Between 1985-1994, we diagnosed six such cases (incidence rate $=1.4$ cases per 10,000 person-years), whilst between 1980-1984 eight cases had been diagnosed (incidence rate $=3.7$ cases per 10,000 person-years). Although, because of the small number of cases, this did not reach statistical significance $(p=0.08)$, we note that the incidence is now considerably lower than before. Had it remained unchanged, we would have expected 17 cases of MPM instead of six.

This drop follows the diminished use of "luto" whitewash (by $92 \%$ of the population in 1950 and only $18 \%$ in 1980). If we take into account a 30-40 year latency period for mesothelioma, we expect that the "Metsovo mesothelioma epidemic" will fade away by the year 2020-2030, since the material has not been used since 1985 . Eur Respir J., 1996, 9, 1206-1210.
\end{abstract}

\begin{abstract}
Depts of *Pulmonary Medicine, **Pathology and \#Epidemiology/Hygiene, University of Ioannina, Medical School, Ioannina, Greece.
\end{abstract}

Correspondence: S.H. Constantopoulos University of Ioannina

Medical School

Ioannina 45110

Greece

Keywords: Malignant mesothelioma nonoccupational asbestos exposure tremolite

Received: July 131995

Accepted after revision January 121996

Presented in Part at the 1995 Annual Congress of The European Respiratory Society.
In 1987, we reported the very high incidence (300 times more than expected) of malignant pleural mesothelioma (MPM) in Metsovo, north-west Greece between 1981-1985 [1]. We attributed this, as well as the endemic occurrence of pleural calcifications (PCs) in the same area (47\% of adult population), to the use of tremolitecontaining whitewash [2-4]. Until then, the inhabitants were unaware of the nature of this material ("luto" soil in the local dialect).

In the present study, we provide a follow-up on the incidence of MPM (between 1985-1994) and compare it to our previous study of the first reported mesotheliomas from Metsovo. Furthermore we hypothesize that the differences in the incidence of MPM may be attributed to the decline in the use of "luto".

\section{Material and Methods}

\section{Population}

The study population comprises the total population of four villages of the Metsovo area (Metsovo, Milia,
Anilio, Votonossi), Ioannina, north-west Greece, which were followed for $15 \mathrm{yrs}, 1980-1994$. Based on the census populations of 1981 and 1991 (4,250 and 4,494, respectively), a linear regression of population by year results in total person-years of 21,372 and 44,574 for the periods 1980-1984 and 1985-1994, respectively. There are no data available on age distribution of the population of the villages.

\section{Cases of malignant pleural mesothelioma}

From January 1985 until December 1994, we diagnosed six MPMs from these villages of the Metsovo area. At the same time, we diagnosed one mesothelioma from another asbestos-exposed area (Pades/Distrato, northwest Greece) [5] and two, from areas of no known exposure. Health services in the District of Ioannina are such that most inhabitants of the Metsovo area are referred to our Hospital, which covers most of north-west Greece, with a population of around 400,000 . These six mesotheliomas were compared with the eight of the period 1980-1984 
from the same villages. The latter eight cases include the seven reported in our original publication [1] and one more, diagnosed one year earlier (1980) by thoracotomy in Athens, and retrospectively studied by us. The last mesothelioma in the previous study was diagnosed late in 1984.

The diagnosis of MPM in the six patients of the period 1985-1994 was obtained by cytological examination of pleural fluid, closed pleural biopsy (Abram's needle) and, in one case, open biopsy. The pathological investigation included: 1) study of the pleural effusions with the combined use of smears and cell block preparations (4 out of 6); 2) study of tissue specimens, after closed needle biopsy ( 5 out of 6 ) or after open chest surgery of the tumour (1 out of 6); and 3) study of fine needle aspiration (FNA) cytological material (1 out of 6) (tables 1 and 2). A modified Papanicolaou stain was used for smears of pleural fluids and FNA material. Haematoxylin and eosin stain was the routine stain for cell block and tissue specimen sections. The special histochemical stains, diastase-periodic-acid and/or mucicarmine and Alcian blue ( $\mathrm{pH} 2.5$ and 1.1) were additionally performed on tissue sections in 2 out of 6 cases (table 2). Immuno-cytochemical and histochemical stains were performed on cell block and tissue specimen sections in 5 out of 6 cases (table 2). The three-stage immunoperoxidase technique was applied by using the monoclonal anti-epithelial membrane antigen (EMA) BER-ER4 antibody (M804 from Dako). The peroxidase-antiperoxidase (PAP) method was applied by using the polyclonal antibody to carcinoembryonic antigen (CEA) (A115 Dako) and the monoclonal antibodies LeuM1 (Becton-Dickinson), anticytokeratin (M821, Dako) anti-vimentin (M725 Dako) $\mathrm{AE}_{1} / \mathrm{AE}_{3}$ (Hybritech) and anti-secretory component (A187 Dako) (table 2) [6-11]

In all patients, detailed "metastatic work-up" was negative for other malignancy with pleural involvement. This included clinical examination fibreoptic bronchoscopy and computerized tomography of chest and abdomen.

The incidence of MPM in the two groups (1980-1984 and 1985-1994) is correlated with the use of "luto". As described previously $[4,5,12]$ this tremolite containing whitewash was used by practically all inhabitants of Metsovo until 1950. Since then it has gradually been replaced by more modern materials, and by 1980 it was used by only $18 \%$ of Metsovites. Now its use has practically ceased (fig. 1).

\section{Statistical evaluation}

Incidence rates with their $95 \%$ confidence intervals (CI) were calculated using the exact method based on Poisson distribution [13]. The age structure of the Metsovo population is not available, so that no standardization can be used and the rates are crude. Using the EpiInfo package, the statistical difference between the rates was tested; one expected value was less than 5 so Chi-squared was invalid and the difference was tested by Fisher's exact test [14]. The relative risk (RR) of having mesothelioma in the period 1980-1984 in relation to the period 1985-1994 was calculated, and also the 95\% CI for the RR using the "test-based" method [13].

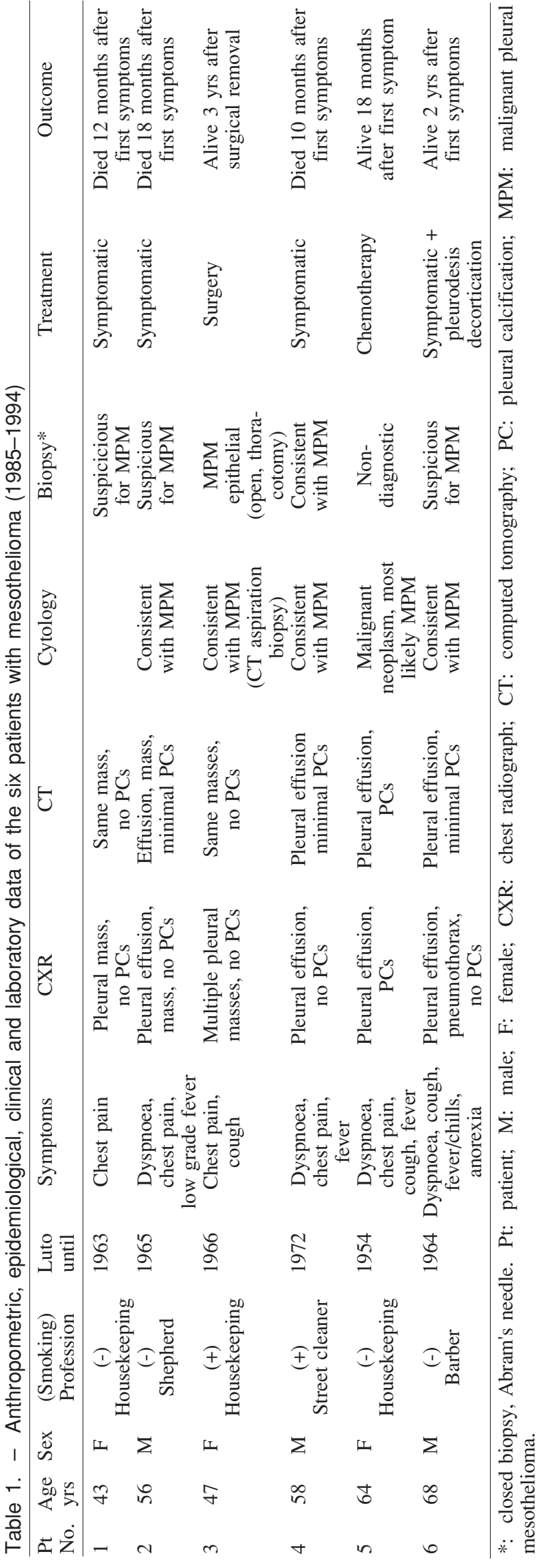


Table 2. - Histochemical and immunohistochemical results

\begin{tabular}{|c|c|c|c|c|c|c|c|c|c|}
\hline \multirow{2}{*}{$\begin{array}{l}\mathrm{Pt} \\
\text { No. }\end{array}$} & \multicolumn{3}{|c|}{ Histochemistry } & \multirow[b]{2}{*}{ EMA } & \multirow[b]{2}{*}{ Keratins } & \multicolumn{2}{|c|}{ Immunohistochemistry } & \multirow[b]{2}{*}{ LeuM1 } & \multirow[b]{2}{*}{$\mathrm{SC}$} \\
\hline & PAS & Mucin & Alcian & & & Vimentin & CEA & & \\
\hline \multicolumn{10}{|c|}{ Tissue specimens } \\
\hline 3 & $(-)$ & $(+/-)$ & $(+/-)$ & & $(+)$ & $(+)$ & $( \pm)$ & $(-)$ & $(-)$ \\
\hline 4 & $(-)$ & $(+/-)$ & & $(+)$ & $(+)$ & $(+)$ & $( \pm)$ & $(-)$ & \\
\hline \multicolumn{10}{|c|}{ Cell block preparations of pleural fluids } \\
\hline 2 & & & & $(+)$ & $(+)$ & $(+)$ & $(-)$ & $(-)$ & \\
\hline 4 & & & & $(+)$ & $(+/-)$ & $(+)$ & $(-)$ & $(-)$ & \\
\hline 5 & & & & $(+)$ & $(+)$ & $( \pm)$ & $(-)$ & $( \pm)$ & \\
\hline 6 & & & & $(+)$ & $( \pm)$ & $(+)$ & $(-)$ & $(-)$ & \\
\hline
\end{tabular}

$(-)$ : negative staining; $(+)$ : positive staining; $( \pm)$ : nonreliable staining; $(+/)$ : positive staining in a few cells. PAS: periodicacid-schiff; EMA: epithelial membrane antigen; CEA: carcinoembryonic antigen; SC: secretory component.

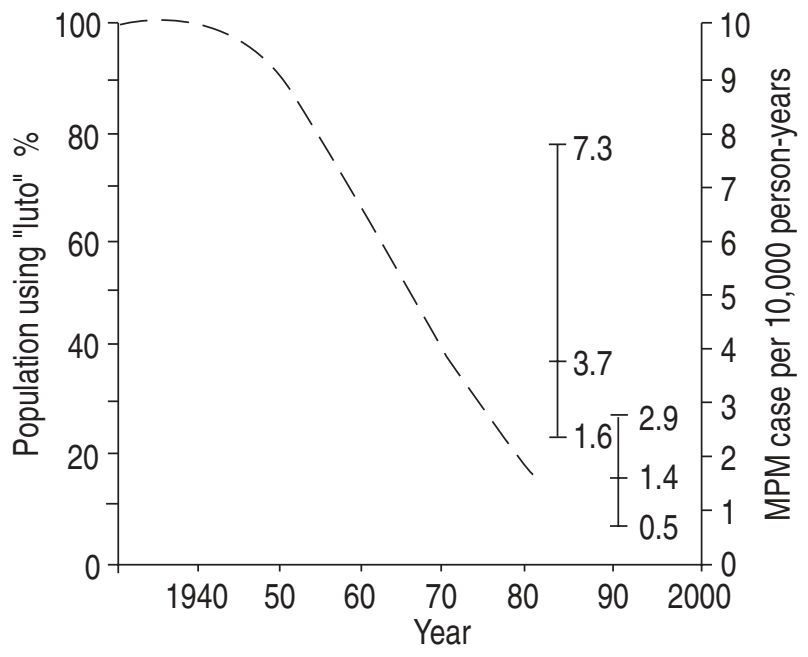

Fig. 1. - The percentage of Metsovites using "luto" (dashed curve) has dropped from practically $100 \%(1940-1950)$ to $71 \%(1960), 38 \%$ (1970) and $18 \%$ (1980). The incidence of malignant pleural mesothelioma (MPM) in the area was 3.7 cases per 10,000 person years $(95 \%$ CI 1.6-7.3) for the period 1980-1984 and 1.4 (95\% CI 0.5-2.9) for the period 1985-1994.

\section{Results}

Anthropometric, epidemiological, clinical and laboratory data are presented in table 1 , and cytological, histological data in table 2.

Our results regarding incidence of MPM between 1980-1984 and 1985-1994 are shown in table 3. The incidence rate was 3.7 cases per 10,000 person-years in 1980-1984 (95\% CI 1.6-7.3), and 1.4 in 1985-1994 (95\% CI 0.5-2.9) (fig. 1). Though the first was 2.8 times greater

Table 3. - The incidence of mesothelioma in the Metsovo area, loannina, Greece during the periods 1980-1984 and 1985-1994

\begin{tabular}{lcc}
\hline & $1980-1984$ & $1985-1994$ \\
\hline Cases n & 8 & 6 \\
Person-years & 21372 & 44574 \\
Incidence rate (cases per & 3.7 & 1.4 \\
10,000 person-years) & & \\
95\% CI for incidence* & $(1.6-7.3)$ & $(0.5-2.9)$ \\
\hline
\end{tabular}

*: exact method based on Poisson distribution; therefore Fisher's test was used. CI: confidence interval. than the second $(\mathrm{RR}=2.8$, with $95 \%$ CI 1.0-7.7), there was no statistically significant difference between the rates, mainly because of the small numbers of cases $(\mathrm{p}=0.08$, Fisher's exact test).

\section{Discussion}

The increased commercial use of asbestos has resulted in a "mesothelioma epidemic" more than 20 yrs later [15]. This "latent period" of $30-40$ yrs $[16,17]$ is typical of all asbestos-related diseases, and MPM is no exception. Thus, in industrialized countries (US, UK, Canada) there were about two deaths from MPM per million per year until the 1950s. Since then, male mortality has risen, in parallel with industrial asbestos consumption $30-40$ yrs earlier. This is expected to continue, for another 20 yrs or so and then start diminishing following the diminishing use of asbestos [17].

In Metsovo, we have documented that the increased incidence of mesothelioma and endemic pleural calcifications are a result of asbestos exposure; more specifically tremolite used for whitewashing [1-4]. This is a rather unique exposure, differing in several aspects from the "usual" occupational exposure. The main differences are: 1) that exposure started very early in life; 2) that it was not continuous; and 3) that it reached extreme values when the material was crushed in preparation for the whitewashing [12].

"Luto" soil was outcropped from nearby hills, shaped into a ball and sold. The women of Metsovo would crush this ball the size of a cannon ball, into fine powder, boil it and apply it to the walls. During crushing, more than 200 fibres $\cdot \mathrm{mL}^{-1}$ air were released into the immediate environment. There was no significant exposure during the other steps of preparation or whitewashing [12]. The material was applied to the interior walls and especially around the fire place because "the wall would not become black from the fire" ("amiantos" in Greek $=$ something that does not get dirty). This procedure was repeated once or twice a year.

Although this was a "woman's job" we observed no sex differences in the incidence of pleural calcifications [2] or mesothelioma [1]. On the other hand, we have discovered PCs in Metsovites who left Metsovo at a very early age (3-5 yrs of age) [3]. Therefore, we speculated that the exposure started at a very early age when women 
took their small children with them during the preparation of "luto". The fact that exposure starts early in life accounts for the younger age of our patients (40-68 yrs, mean $51 \mathrm{yrs}$ ) than that of males exposed to asbestos occupationally (peak at 51-70 yrs) [18]

"Luto" was used by practically all households until 1940-1950. It was then gradually substituted by more modern and more convenient materials and now it is, presumably, not used since its consequences were made clear to the inhabitants in the early 1980s (fig. 1).

The first definite case of mesothelioma from Metsovo occurred in 1980. It was, however, a retrospective observation made by us, after we witnessed the "mesothelioma epidemic" of 1981-1985 [1]. This was immediately after the Pulmonary Department was established in Ioannina in 1981. We have no way of knowing whether or not there were other cases of mesothelioma before 1980, but there is no record of mesothelioma in any death certificate before 1980 or in the records of Ioannina General Hospital. This is also mentioned in the study of BAZAS and co-workers [19, 20].

Judging from the declining use of "luto", we hypothesized in 1989 [21] that "the epidemic is fading and we will be seeing less and less in the next 10-20 years and the epidemic will complete its cycle in a few decades". The incidence rate of MPM between 1985-1994 appears to support this hypothesis. Compared to 1980-1984, we have a drop from 3.74 to 1.35 cases per 10,000 personyears, in roughly the same, possibly slightly older, population (4,250 in 1981 and 4,494 in 1991). Though the difference did not prove statistically significant, we cannot ignore that it is now 2.8 times lower than then. Of course it is still very high compared to that of 1-2 million $\cdot \mathrm{yr}^{-1}$ in nonasbestos exposed population [18], or our own two cases in 10 yrs per 400,000 population nonexposed.

We mentioned previously that we cannot be certain that there were no mesotheliomas before 1980. It is also possible that we have missed some cases between 19851994, although, again, there is no such evidence from death certificates or hospital records. If so, we see no reason to have missed more MPMs than in the first period (1980-1984), since our Department has in the mean time established itself as a referral centre.

There is also the theoretical possibility that we have relatively underestimated the incidence in the last $10 \mathrm{yrs}$ because, unlike the first years, we now have most modern cytological/histological techniques available to rule out MPM and diagnose a metastatic malignancy. This also is not the case, since there were no patients with metastatic malignancy to the pleura without obvious primary focus from Metsovo in the last 10 yrs in our Department.

Finally, as mentioned previously, if the population of Metsovo has become older between 1980 and 1994, we may, if anything, have overestimated the incidence of mesothelioma for the second period (1985-1994). Therefore, we consider that the drop in the incidence rate is genuine.

As shown in figure 1 this drop in incidence rate follows the diminishing use of tremolite whitewash from $92 \%$ of the population in 1950 to $71 \%$ in 1960 and $38 \%$ in 1970 with a "latency period" of 30-40 yrs, as is expected for mesothelioma. This temporal relationship does not establish a causative relationship. In fact, the drop in incidence rate appears too abrupt to be attributed only to the diminished use of "luto", but then one or two cases missed or simply not occurring exactly at the "expected year" could make all the difference. Thus, one case more in the period 1980-1984 would have made the difference statistically significant ( 9 cases in 1980-1984 versus 6 cases in 1985-1994; $\mathrm{p}=0.028$, Fisher exact 2-tailed), while one case less between 1985-1994 would have made the correlation with diminished use of "luto" more convincing.

We do not have information regarding the age structure of our study population. For the whole of Greece birth and death rates are falling during all study periods, and the population becomes increasingly "aged". There is no reason for the study population not to follow these changes, and we reasonably believe that it is now older than in 1980-1984. Between two censuses it grew by only 244 persons $(5.7 \%)$, a difference which seems to be explained by the difference of birth and death rates (approximately around 15 and 10\%, respectively). For the same reason, we do not believe that there were (at least any remarkable) migration movements that could account for this "disproportionate" drop in incidence rate (e.g. movement of young people to other cities where their MPM was diagnosed).

However, since the use of "luto" dropped even more dramatically after 1970 , resulting in practical abandonment of this material after 1985-1990, we can expect a further decline of the incidence of MPM in Metsovo in the next decades and hopefully its disappearance by the year 2020-2030 (30-40 yrs after 1990).

This expectation will certainly be tested in the future and further data will be needed from continued followup. However, we considered it appropriate to report this declining incidence now, 10 years after our last report. After all, it is not bad to report "good news", and it is "good news" to have only six cases of MPM instead of an "expected" 17 cases if the incidence had remained the same.

It is of interest that our expectation of a possible slow end to this "Metsovo mesothelioma epidemic" is similar to that recently expressed by PETO and co-workers [22]. In spite of the completely different title of their article ("Continuing increase in mesothelioma mortality in Britain") the conclusions are similar. Namely, based on the annual asbestos imports in Britain and the annual mesothelioma deaths in men born before 1953, they predict that these deaths will keep rising until around 2020 and will then drop dramatically by the year 2040 .

Although we are certainly dealing with completely different populations, British asbestos workers born before 1953 and exposed 20 yrs later to the most intense use of asbestos in Britain, could be considered comparable to Metsovites born before 1950-1955 and exposed since childhood to tremolite when "luto soil" was used by practically all households.

It is, therefore, not unreasonable to expect a slow end to this epidemic by 2020-2030. If this occurs, it will be quite similar to the situation in the USA, where the "mesothelioma epidemic" has already reached its peak [23]. Overall cases there are likely to fall reflecting the pattern of asbestos use, which reached a plateau soon after World War II [24] and diminished in the following decades, just like the use of "luto soil" in Metsovo. 


\section{References}

1. Constantopoulos SH, Malamou-Mitsi V, Goudevenos J, Papathanasiou MP, Pavlidis NA, Papadimitriou CS. High incidence of malignant pleural mesothelioma in neighbouring villages of north-west Greece. Respiration 1987; 51: 266-271.

2. Constantopoulos SH, Goudevenos JA, Saratzis N, Langer AE, Selikoff IJ, Moutsopoulos HM. Metsovo lung: pleural calcifications and restrictive lung function in northwestern Greece: environmental exposure to mineral fiber as etiology. Environ Res 1985; 38: 319-331.

3. Langer AM, Nolan RP, Constantopoulos SH, Moutsopoulos HM. Association of Metsovo lung and pleural mesothelioma with exposure to tremolite-containing whitewash. Lancet 1987; i: 965-967.

4. Constantopoulos SH, Saratzis NA, Goudevenos JA, Kontogiannis D, Karantanas A, Katsiotis P. Tremolite whitewashing and pleural calcifications. Chest 1987; 92: 709-712.

5. Constantopoulos SH, Theodoracopoulos P, Dascalopoulos G, Saratzis NA, Sideris K. Metsovo lung outside Metsovo: endemic pleural calcifications in the ophiolite belts of Greece. Chest 1991; 99: 1158-1161.

6. Whitaker D, Shilkin KB. Diagnosis of pleural malignant mesothelioma in life: a practical approach. J Pathol 1984; 143: 147-175.

7. Jones JSP. Pathology of mesothelioma. Eur Respir Rev 1993; 11: 22-24.

8. Ordonez NG. The immunohistochemical diagnosis of mesothelioma: differentiation of mesothelioma and lung adenocarcinoma. Am J Surg Pathol 1989; 13: 276-291.

9. Mason MR, Bedrossian CWM, Fahey CA. Value of immunocytochemistry in the study of malignant effusions. Diagn Cytopathol 1987; 3: 215-221.

10. Duggan MA, Masters CB, Alexander F. Immunohistochemical differentiation of malignant mesothelioma, mesothelial hyperplasia and metastatic adenocarcinoma in serous effusions, utilizing staining for carcinoembryonic antigen, keratin and vimentin. Acta Cytol 1987; 31: 807-814.

11. Diaz-Arias AA, Loy TS, Bickel JT, Chapman RK. Utility of BER-ER4 in the diagnosis of adenocarcinoma in effusions: an immunocytochemical study of 232 cases. Diagn Cytopathol 1993; 9: 516-521.

12. Constantopoulos SH, Dalavanga YA, Sakellariou K,
Goudevenos J and Kotoulas OB. Lymphocytic alveolitis and pleural calcifications in nonoccupational asbestos exposure: protection against neoplasia? Am Rev Respir Dis 1992; 146: 1565-1570.

13. Ahlbom A. In: Biostatistics for Epidemiologists. Lewis Publishers, 1993; pp. 56-68.

14. Pearson JCG, Turton A. Statistical Methods in Environmental Health. Chapman and Hall, 1993; p. 95.

15. McDonald JC. Asbestos-related disease: and epidemiological review. In: Wagner JC, ed. Biological Effects of Mineral Fibres. IARC Scientific Publications, No. 30. Lyon, International Agency for Research on Cancer, 1980; pp. 587-601.

16. Roggli VL, San Filippo E, Shelburne JD. Mesothelioma. In: Roggli VL, Greenberg SD, Pratt PC, eds. Pathology of Asbestos-associated Diseases. Little Brown, 1992; pp. 109-164.

17. McDonald JC. Health implications of environmental exposure to asbestos. Environ Health Perspect 1985; 62: 319-328.

18. Hillerdal G. Malignant mesothelioma, 198: review of 4,710 published cases. Br J Dis Chest 1983; 77: 321-343.

19. Bazas T, Bazas B, Kitas D, Gilson JC, McDonald JC. Pleural calcification in north-west Greece. Lancet 1981; i: 254 .

20. Bazas T, Oakes D, Gilson JC, Bazas B, McDonald JC. Pleural calcification in north-west Greece. Environ Res 1985; 38: 239-247.

21. Constantopoulos SH. Epidemiology, clinical picture and diagnosis of mesothelioma. In: Constantopoulos $\mathrm{SH}$, Pavlidis NA, eds. Bronchogenic Carcinoma and Mesothelioma. Editions of University of Ioannina, 1989, (Greek).

22. Peto J, Hodgson JT, Matthews FE, Jones JR. Continuing increase in mesothelioma mortality in Britain. Lancet 1995; 345: 535-539.

23. Health Effects Institute. Asbestos research. Asbestos in public and commercial building: a literature review and synthesis of current knowledge. Cambridge, MA; Health Effects Institute, 1991.

24. Peto J, Henderson BE, Pike MC. Trends in mesothelioma incidence in the United States and the forecast epidemic due to asbestos exposure during World War II. In: Peto R, Schneiderman M, eds. Quantification of Occupational Cancer. Banbyry Report 9, Cold Spring Harbor Laboratory, 1981. 